\title{
Mechanism of resistance to chemoradiation in $p 53$ mutant human colon cancer
}

\author{
JUNICHIRO HIRO, YASUHIRO INOUE, YUJI TOIYAMA, CHIKAO MIKI and MASATO KUSUNOKI \\ Department of Gastrointestinal and Pediatric Surgery, Division of Reparative Medicine, Institute of Life Sciences, \\ Mie University Graduate School of Medicine, Tsu, Mie 514-8507, Japan
}

Received February 5, 2008; Accepted March 21, 2008

\begin{abstract}
To understand one of the mechanisms of resistance to chemoradiation in colon cancer cells, we investigated whether 5-fluorouracil (5-FU) mediated the expression of epidermal growth factor receptor (EGFR) and modified repair of radiation-induced DNA damage, especially in a p53 independent pathway. Cytotoxicity was determined for 5-FU combined with radiation for three colon cancer cell lines that contain mutant p53 (SW480, HT29 and WiDr), using the WST-8 colorimetric assay. EGFR and the excision repair cross complementation group 1 (ERCC1) proteins during chemoradiation were measured by Western blot analysis. SW480 cells were significantly resistant to chemoradiation compared to the other mutant p53 cell lines. The alteration of EGFR and ERCC1 proteins during chemoradiation in SW480 was apparently inversely related to that of the other radiosensitive cell lines. 5-FU-induced activation of EGFR followed by radiation in SW480 cells resulted in up-regulation of ERCC1. In contrast, 5-FU-induced degradation of EGFR followed by radiation in the other radiosensitive cell lines resulted in down-regulation of ERCC1. This suggested a complementary interaction between EGFR and ERCC1, and that 5-FU-induced EGFR activation conferred protection against radiation, through activation of DNA repair. Interaction of EGFR and ERCC1 might correlate with radiation-induced DNA damage when p53 mutant colon cancer cell lines are exposed to 5-FU followed by radiation.
\end{abstract}

\section{Introduction}

Chemoradiotherapy is now widely used for the definitive and adjuvant treatment of the majority of cancer patients. Randomized trials have shown that combination treatment

Correspondence to: Dr Masato Kusunoki, Department of Gastrointestinal and Pediatric Surgery, Division of Reparative Medicine, Institute of Life Sciences, Mie University Graduate School of Medicine, Edobashi 2-174, Tsu, Mie 514-8507, Japan

E-mail: kusunoki@clin.medic.mie-u.ac.jp

Key words: colon cancer, chemoradiation, EGFR, ERCC1 improves survival compared with radiation alone in locally advanced cancers of the head and neck (1), lung (2), esophagus (3), stomach (4) and rectum (5). Over the past decades, interest in preoperative chemoradiotherapy for resectable rectal cancer has increased, since it has the advantage of enhancing locoregional control by eliminating microscopic residual disease around the primary tumor and in the draining lymphatics, with a possible positive impact on overall survival (5). Although chemoradiotherapy for resectable rectal cancer is now widely accepted because of resounding clinical successes, current practices with regard to radiation technique and chemotherapy regimen differ between countries, and even between institutions. Thus, the issue of optimal chemoradiotherapy for rectal cancer is one of the major controversies in the field of oncology. In particular, resistance to chemoradiotherapy remains an important concern, because some patients show no response and suffer side-effects despite intensive therapy.

Therefore, more accurate selection of patients who are suitable for preoperative chemoradiotherapy and understanding of resistance mechanisms should improve both oncological and surgical results. However, the mechanisms of resistance to chemoradiotherapy regimens remain largely unknown. In recent years, several approaches have been pursued toward specific modulation of defined pathways of cell death, in order to increase the therapeutic efficacy of radiation and/or reduce radiation-mediated side-effects, irrespective of concurrent chemotherapy.

The epidermal growth factor receptor (EGFR) is a $170-\mathrm{kDa}$ cell surface receptor that plays a pivotal role in cell proliferation, migration and survival. Overexpression of EGFR correlates with tumor resistance to cytotoxic agents, including radiation, increased cancer relapse rate, and poor survival (6-8). Multiple lines of evidence indicate that EGFR is an important determinant of radiation response and has a radioprotective function (9). Although various intrinsic and extrinsic factors affecting radiosensitivity, including hypoxia and angiogenesis (10), DNA repair (11) and p53 gene status (12), have been reported, as well as EGFR status, we focused on the expression of EGFR and DNA repair, which may be potential mechanisms of chemo-radiosensitivity in p53 mutant human colon cancer cells.

In the present study, to understand one of the chemoradioresistant mechanisms in colon cancer cells, we investigated whether 5-FU, which has been used extensively with radiation for colorectal cancer, mediated the expression of 
EGFR, and modified repair of radiation-induced DNA damage, especially via a p53-independent pathway.

\section{Materials and methods}

Cell culture. The three p53 mutant type human colon adenocarcinoma cell lines (SW480, HT29 and WiDr) were obtained from the Cell Resource Center for Biomedical Research, Institute of Development, Aging and Cancer, Tohoku University, Japan. These cell lines were grown in RPMI-1640 (Sigma-Aldrich, St. Louis, MO, USA), supplemented with fetal bovine serum [10\% (v/v); Gibco BRL, Tokyo, Japan], glutamine $(2 \mathrm{mM})$, penicillin $(1,000,000 \mathrm{U} / \mathrm{l})$, streptomycin $(100 \mathrm{mg} / \mathrm{l})$ at $37^{\circ} \mathrm{C}$ in a $5 \% \mathrm{CO}_{2}$ incubator.

Anticancer agents. 5-FU was obtained from Sigma-Aldrich, reconstituted in distilled water at appropriate concentrations, and stored at $-20^{\circ} \mathrm{C}$ until use.

Experimental protocol. We used clinical concentrations of 5-FU as much as possible, which were chosen based on our previous reports $(13,14)$ and drug information obtained from Kyowa Hakko Kogyo (Tokyo, Japan). The drug information on 5-FU indicated that the plasma concentration reaches $15.3 \mu \mathrm{g} / \mathrm{ml}(100 \mu \mathrm{M})$ after a bolus injection of $500 \mathrm{mg} / \mathrm{m}^{2}$, and $0.6 \mu \mathrm{g} / \mathrm{ml}(5 \mu \mathrm{M})$ during continuous infusion of 5 -FU $(60 \mathrm{mg} / \mathrm{kg} / 48 \mathrm{~h})$. In order to elucidate the radiation effect in detail, radiation was carried out at different doses $(0,2.5$ and $5 \mathrm{~Gy}$ ). All radiation treatments were performed using the CLINAC 2100C X-ray system (Varian Oncology Services, USA) at $4 \mathrm{MV}$, using a 40-mm solid water phantom, with a dose rate of $217 \mathrm{cGy} / \mathrm{min}$.

Chemoradiation schedules. As mentioned above, we used clinically relevant concentrations of 5-FU. Although we should ideally have considered the doubling time of each cell line before deciding the exposure time, we chose to use an exposure of $24 \mathrm{~h}$ for 5 -FU, for experimental simplicity. The final concentrations ranged from 0.1 to $1000 \mu \mathrm{M}$ for 5 -FU. To test the cytotoxicity of each drug, each cell line was treated for $24 \mathrm{~h}$ with various concentrations of 5-FU. After discarding the medium that contained drug and replacing it with fresh medium, cytotoxicity was evaluated using a 2 (2-methoxy-4-nitrophenyl)-3-(4-nitrophenyl)-5-(2,4disulfophenyl)-2H-tetrazolium, monosodium salt (WST-8) colorimetric assay.

For radiation experiments, each cell line was treated with clinical concentrations of 5-FU for $24 \mathrm{~h}$. After removing the drugs from the wells and refilling with fresh medium, radiation was carried out at different doses. The irradiated cells were incubated for 0 or 24 or $48 \mathrm{~h}$, and cytotoxicity was evaluated using a WST- 8 colorimetric assay. The drug exposure and radiation schedules are summarized in Table I.

Growth inhibition assay. Cytotoxicity was evaluated using a WST-8 colorimetric assay. WST-8 is a modification of the MTT assay, which was applied to estimation of cellular viability, using a commercially available kit (Cell Counting Kit; Dojindo Laboratories, Japan) according to the manufacturer's instructions.
Table I. Experimental protocol.
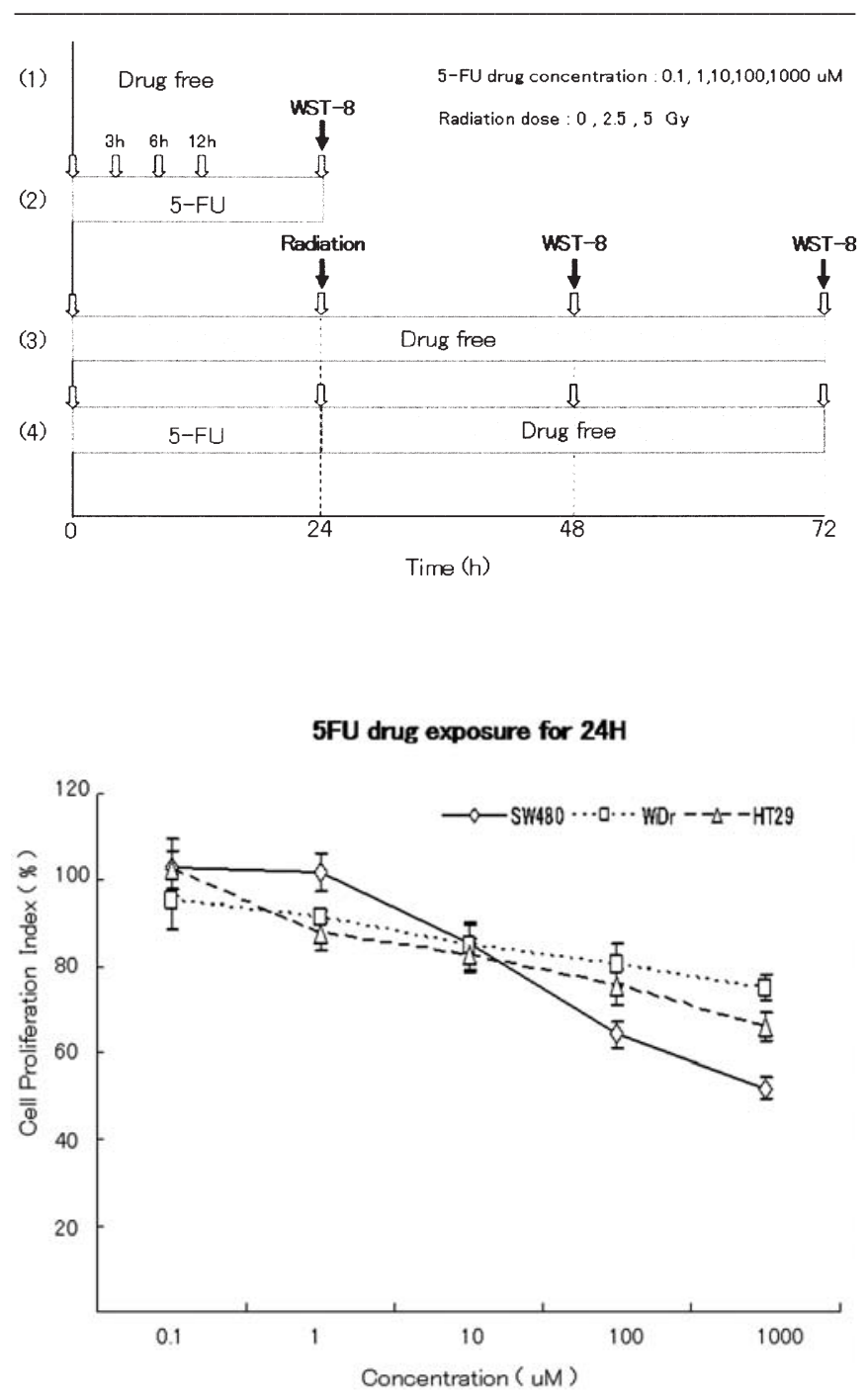

Figure 1. 5-FU dose-dependently inhibited SW480, HT29 and WiDr cell growth. 5-FU concentrations $>10 \mu \mathrm{M}$ were defined as the cytotoxic dose from each survival curve.

Western blot analysis. Protein extraction was carried out as previously described (15). The cells were homogenized in lysis buffer (Tris-buffered saline, $\mathrm{pH} 7.5$, containing $2 \%$ Triton $\mathrm{X}-100$ ) for $5 \mathrm{~min}$ on ice. The protein concentration was measured by the BCA protein assay (Pierce, Rockford, IL, USA). Protein samples $(20 \mu \mathrm{g})$ were solubilized in sample buffer by boiling and then subjecting to SDS-PAGE, followed by electrotransfer onto an Immun-Blot PVDF membrane (Bio-Rad Laboratories, Hercules, CA, USA). Membranes were incubated with an appropriate primary antibody and then with peroxidase-conjugated secondary antibody. Immune complexes were visualized with the enhanced chemiluminescence Western blotting detection system (CS Analyzer version 2.0; ATTO, Japan).

The primary antibodies used were: mouse monoclonal anti- the excision repair cross complementation group 1 (ERCC1) antibody (1:250 dilution; Santa Cruz Biotechnology), a mouse monoclonal anti-EGFR antibody (1:400 dilution; Cell Signaling Technology) and mouse monoclonal anti-actin 
Table II. 5-FU drug exposure for $24 \mathrm{~h}$.

\begin{tabular}{|c|c|c|c|c|c|}
\hline & $0.1 \mu \mathrm{M}$ & $1 \mu \mathrm{M}$ & $10 \mu \mathrm{M}$ & $100 \mu \mathrm{M}$ & $1000 \mu \mathrm{M}$ \\
\hline SW480 & $102.91 \pm 6.39$ & $101.78 \pm 4.52$ & $85.23 \pm 4.48^{a}$ & $64.33 \pm 3.03^{\mathrm{a}}$ & $51.98 \pm 2.34^{\mathrm{a}}$ \\
\hline WiDr & $95.05 \pm 6.45$ & $91.50 \pm 1.14$ & $84.47 \pm 4.21^{\mathrm{a}}$ & $80.62 \pm 4.82^{\mathrm{a}}$ & $75.09 \pm 2.83^{\mathrm{a}}$ \\
\hline HT29 & $102.39 \pm 4.56$ & $87.68 \pm 3.87$ & $82.34 \pm 3.87^{a}$ & $75.21 \pm 4.22^{\mathrm{a}}$ & $66.08 \pm 3.51^{\mathrm{a}}$ \\
\hline
\end{tabular}

Cell proliferation index $\pm \mathrm{SD}(\%) .{ }^{\mathrm{a}} \mathrm{P}<0.05$.

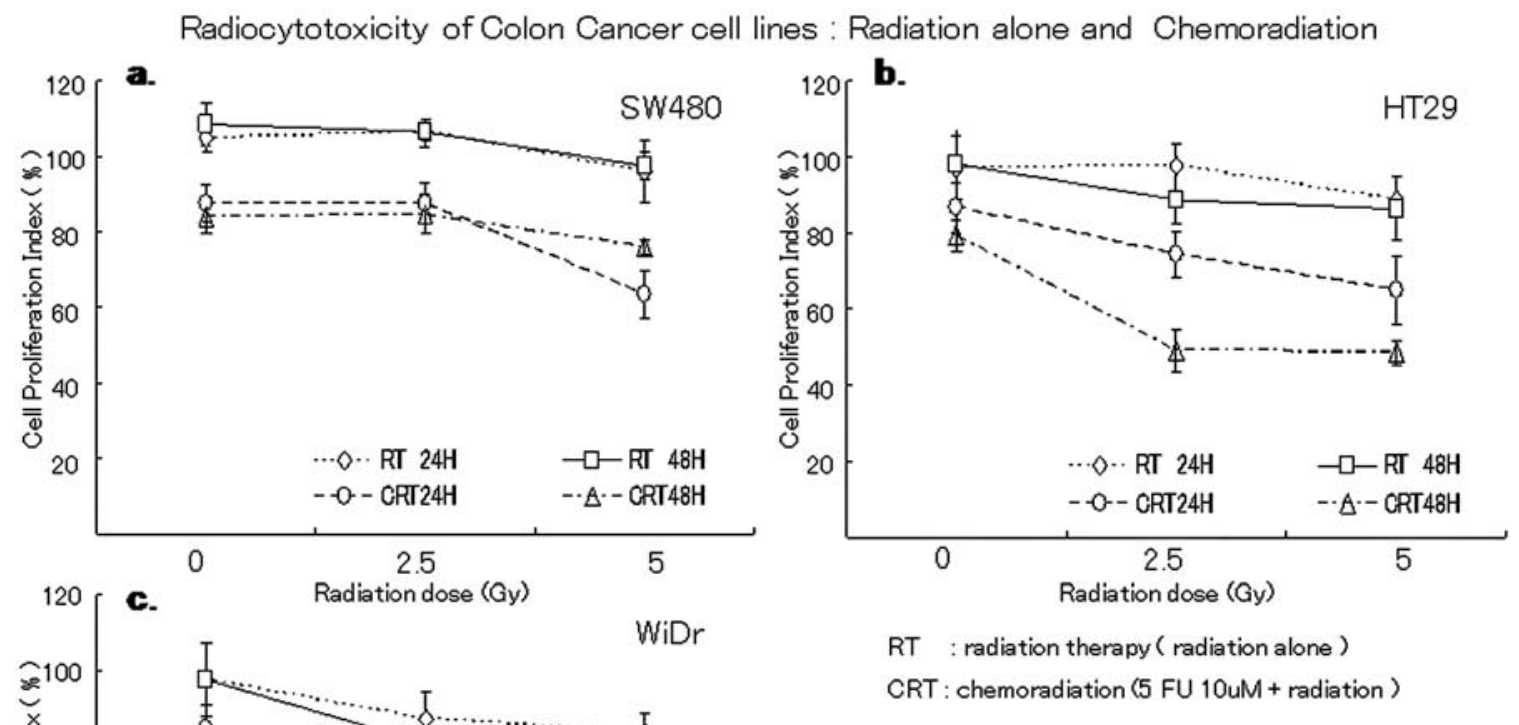

(clone C4) antibody (1:1000 dilution; ICN Biomedicals, Aurora, OH, USA). The secondary antibody was alkaline phosphatase-conjugated goat anti-mouse IgG (Promega, Madison, WI, USA) diluted 1:1000.

Statistical analysis. The results are expressed as the means \pm SD. The Mann-Whitney U test was used for comparisons between unpaired groups. $\mathrm{P}<0.05$ was considered statistically significant.

\section{Results}

Cell growth inhibition of each colon cancer cell line by 5-FU. We evaluated the effects of 5-FU at $0.1-1000 \mu \mathrm{M}$ on cell growth inhibition. The cytotoxic effects of 5-FU were assessed at $24 \mathrm{~h}$ after drug exposure, using the WST- 8 colorimetric assay. 5-FU dose-dependently inhibited SW480, HT29 and WiDr cell growth (Fig. 1 and Table II). We defined the cytotoxic dose of 5 -FU as $>10 \mu \mathrm{M}$, from each survival

curve. Therefore, the minimum cytotoxic dose of 5-FU for each cell line was $10 \mu \mathrm{M}$.

Cell growth inhibition by 5-FU pretreatment and radiation. SW480, HT29 and WiDr cells were treated with 5-FU at $10 \mu \mathrm{M}$ for $24 \mathrm{~h}$. After removing the fresh drug-free medium, each sample was irradiated at room temperature $\left(22-25^{\circ} \mathrm{C}\right)$. The radiation dose ( 2.5 and $5 \mathrm{~Gy}$ ) was chosen because it represented a clinically relevant radiotherapeutic dose. Cell growth inhibition was assessed by WST- 8 colorimetric assay. To measure the radio-enhancing effect of 5-FU on cancer cells, we calculated the growth ratio of viable cells at 0 and $24 \mathrm{~h}$, and at 0 and $48 \mathrm{~h}$.

In all cell lines, growth inhibition was shown to be greater following chemoradiation than that after radiation alone. 5-FU $10 \mu \mathrm{M}$ combined with 2.5 or 5 Gy radiation inhibited HT29 and WiDr cell growth in a time-dependent manner, however, the radio-enhancing effect in SW480 cells was found only at a radiation dose of 5 Gy (Fig. 2 and Table III). 
Table III. Radiocytotoxicity of colon cancer cell lines: radiation alone and chemoradiation.

\begin{tabular}{|c|c|c|c|c|}
\hline & & 0 Gy & $2.5 \mathrm{~Gy}$ & 5 Gy \\
\hline \multirow[t]{4}{*}{ SW480 } & RT $24 \mathrm{~h}$ & $105.00 \pm 3.82$ & $106.45 \pm 3.71$ & $96.11 \pm 7.90$ \\
\hline & CRT $24 \mathrm{~h}$ & $87.49 \pm 5.08^{\mathrm{a}}$ & $87.57 \pm 5.61^{\mathrm{a}}$ & $63.40 \pm 6.27^{a}$ \\
\hline & RT $48 \mathrm{~h}$ & $108.52 \pm$ & 106.50 & $97.52 \pm 3.72$ \\
\hline & CRT 4 & $85.23 \pm 4.48^{a}$ & $84.67 \pm 5.09^{\mathrm{a}}$ & $76.00 \pm 1.81^{\mathrm{a}}$ \\
\hline \multirow[t]{4}{*}{ HT29 } & RT $24 \mathrm{~h}$ & $97.07 \pm 8.43$ & $97.89 \pm 5.84$ & $88.95 \pm 5.86$ \\
\hline & CRT 24 h & $86.67 \pm 6.61^{\mathrm{a}}$ & $74.50 \pm 5.84^{a}$ & $64.79 \pm 8.97^{a}$ \\
\hline & RT $48 \mathrm{~h}$ & $97.97 \pm 9.07$ & $88.53 \pm 6.38$ & $86.22 \pm 7.65$ \\
\hline & CRT $48 \mathrm{~h}$ & $82.34 \pm 3.87^{\mathrm{a}}$ & $49.24 \pm 5.43^{\mathrm{a}}$ & $48.36 \pm 3.40^{\mathrm{a}}$ \\
\hline \multirow[t]{4}{*}{ WiDr } & RT $24 \mathrm{~h}$ & $97.49 \pm 9.76$ & $87.14 \pm 7.17$ & $83.60 \pm 4.87$ \\
\hline & CRT $24 \mathrm{~h}$ & $84.81 \pm 5.59^{\mathrm{a}}$ & $70.77 \pm 8.11^{\mathrm{a}}$ & $63.35 \pm 6.39^{a}$ \\
\hline & $\mathrm{RT} 48 \mathrm{~h}$ & $97.49 \pm 9.76$ & $80.90 \pm 9.64$ & $81.88 \pm 5.40$ \\
\hline & CRT $48 \mathrm{~h}$ & $79.47 \pm 4.21^{\mathrm{a}}$ & $57.64 \pm 5.88^{\mathrm{a}}$ & $41.28 \pm 5.00^{\mathrm{a}}$ \\
\hline
\end{tabular}

Cell proliferation index $\pm \mathrm{SD}(\%)$. ${ }^{\mathrm{P}}<0.05$. RT, radiation therapy (radiation alone). CRT, chemoradiation 5-FU + radiation).

Fig. 3 shows the cytotoxicity of 2.5 Gy in all cell lines. Interestingly, SW480 was significantly resistant to chemoradiation compared to the other radioresistant cell lines. To understand the radioresistant effect of pretreatment with low cytotoxic doses of 5-FU, we searched for other possible contributory factors, including EGFR and ERCC1.

Alteration of EGFR and ERCC1 proteins during chemoradiation. Fig. 4 shows the alteration of EGFR and ERCC1 proteins during 24-h exposure to 5-FU. Exposure to 5-FU up-regulated EGFR and simultaneously down-regulated ERCC1 expression in radio-resistant SW480 cells. In contrast, exposure to 5-FU down-regulated EGFR and simultaneously up-regulated ERCC1 expression in radio-sensitive cell lines.

Additionally, the alteration of EGFR and ERCC1 proteins during chemoradiation in SW480 was apparently inversely related to that of the other radiosensitive cell lines. 5-FUinduced activation of EGFR followed by radiation in SW480 cells resulted in up-regulation of ERCC1. In contrast, 5-FUinduced degradation of EGFR followed by radiation in the other radio-sensitive cell lines resulted in down-regulation of ERCC1 (Fig. 5).

\section{Discussion}

It is well established that EGFR is one of the key players during regulation of cellular stress responses to chemotherapy and radiotherapy $(16,17)$. EGFR not only regulates cell proliferation, but is also important for the regulation of cell survival and DNA repair (16-18). However, it is poorly understood whether alterations in EGFR and DNA repair during treatment can affect radiation sensitivity of colorectal cancer (CRC), since the optimal chemoradiation schedule for CRC is still undefined clinically.

In this study, we used three human adenocarcinoma cell lines with mutant p53, SW480, WiDr and HT29, because mutation of the p53 gene have been found in $\sim 50 \%$ of CRC, and is associated with resistance to chemotherapy and radiation $(19,20)$. We first attempted to establish the range of optimal concentration for 5-FU pretreatment and radiation doses based on our previous attempts to obtain radioenhancement and cell growth inhibition in three cell lines $(13,14,21)$. SW480 cells were significantly resistant to chemoradiation

Radiocytotoxicity of 2.5Gy : Radiation alone and Chemoradiation

Radiation dose 2.5Gy

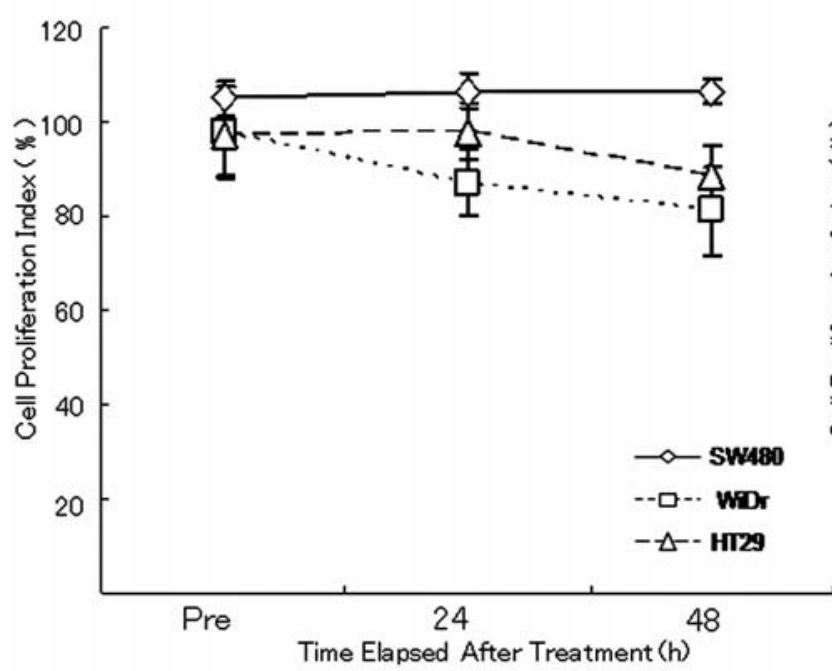

Chemoradiation (5FU10uM and 2.5Gy)

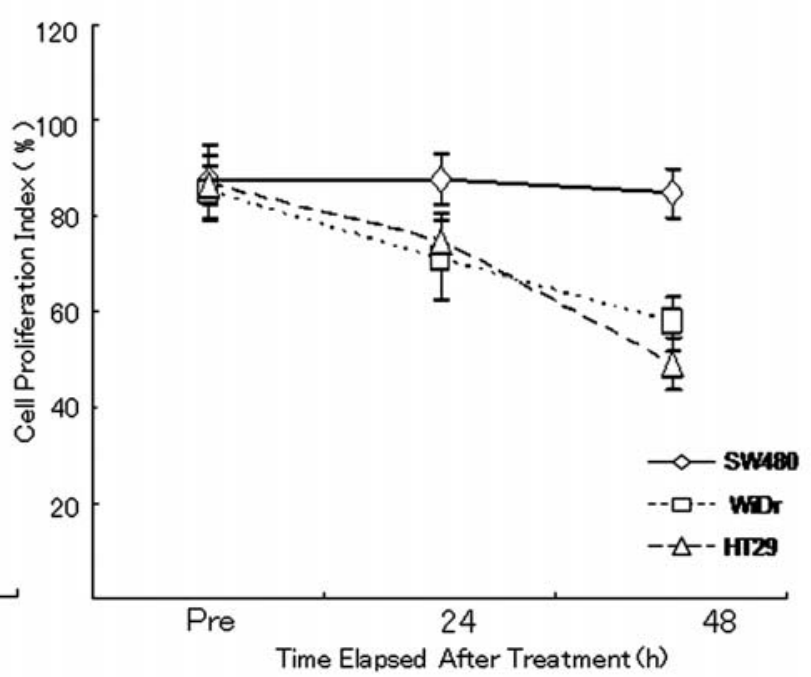

Figure 3. Despite the minimum cytotoxic dose of 5-FU and radiation, SW480 cells were significantly resistant to chemoradiation compared to other radioresistant cell lines. 
ERCC1

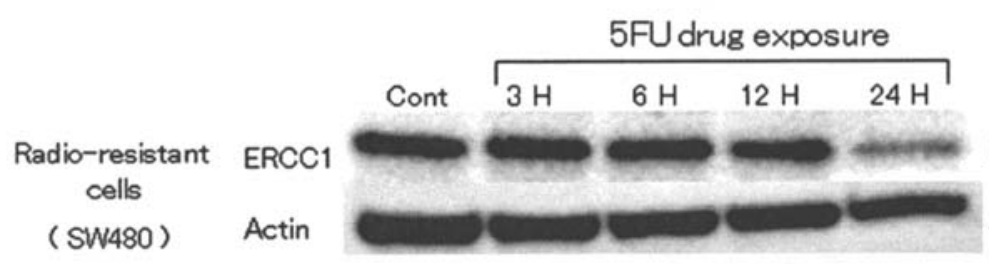
Radio-sensitive
cells
(WiDr)

\section{ERCC1 \\ Actin}

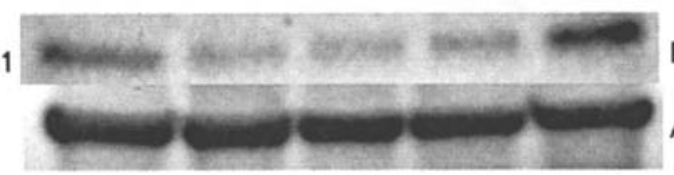

\section{EGFR}

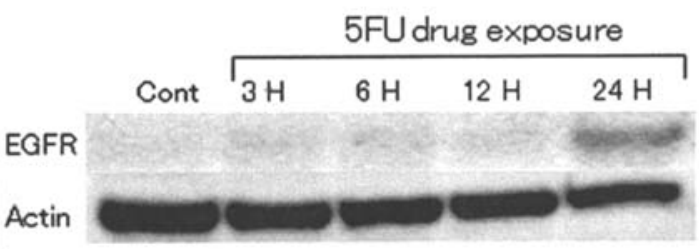

EGFR

Actin

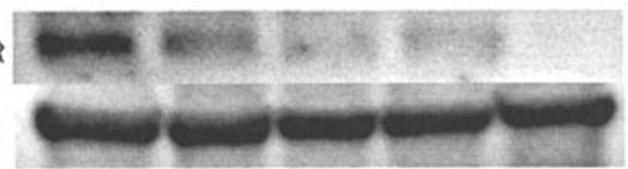

Figure 4. Exposure to 5-FU up-regulated EGFR and simultaneously down-regulated ERCC1 expression in radio-resistant SW480 cells. In contrast, exposure to 5-FU down-regulated EGFR and simultaneously up-regulated ERCC1 expression in radio-sensitive cell lines.
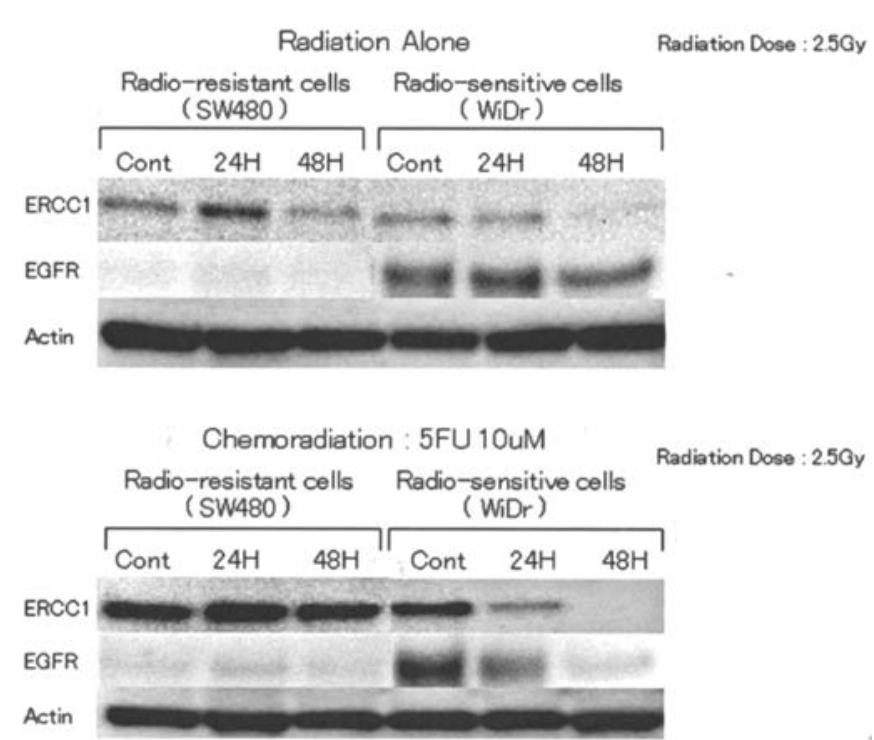

Figure 5. Alteration of EGFR and ERCC1 proteins during chemoradiation in SW480 cells was apparently inversely related to that in other radiosensitive cell lines. After chemoradiation, up-regulation of EGFR in SW480 was maintained.

compared to the other mutant p53 cell lines. To understand the radioresistant effect of pretreatment with low cytotoxic doses of 5-FU, we searched for other possible contributory factors.

Based on current evidence, EGFR-mediated radioresistance can be conceptually divided into three phases: a) an immediate early phase that involves DNA repair; b) suppression of DNAdamage-induced apoptosis before and after cell cycle arrest; and c) a tumor repopulation step that offers a proliferative advantage to tumors emerging from radiation-induced cell cycle arrest (9). Although a functional connection between EGFR and the DNA double-strand breakage repair including DNA-dependent protein kinase (DNA-PK) was reported recently (22). However, there is little information on the interaction between EGFR alterations during chemoradiation and the nucleotide excision repair pathway.

The nucleotide excision repair pathway is one of the most important that guards the integrity of the genome, which removes a wide variety of DNA lesions, including interstrand cross-links caused by cisplatin or radiation $(23,24)$. Removal of these adducts from genomic DNA is mediated by a complex interaction of various proteins $(25,26)$. A critical step in this process is the interaction of the product of the ERCC1 gene with those of the Xeroderma pigmentosum Group A (XPA) and group F (XPF) genes (27). A recent study has shown that decreased ERCC1 mRNA expression is a predictor for response to neoadjuvant chemoradiation for esophageal cancer (28). Experimental studies have demonstrated that increased ERCC1 levels are associated with removal of cisplatininduced strand adducts, and relative cisplatin resistance (23). In addition, ERCC1-defective knockout mice are highly sensitive to DNA cross-linking agents (29). ERCC1 is associated with radiation-induced DNA damage, although this mechanism is still poorly understood $(30,31)$.

In the present study, the alteration of EGFR and ERCC1 proteins during chemoradiation in SW480 cells was apparently inversely related to that of the other radiosensitive cell lines. We showed that 5-FU-induced activation of EGFR followed by radiation in SW480 cells resulted in up-regulation of ERCC1. In contrast, 5-FU-induced degradation of EGFR followed by radiation in radiosensitive cell lines resulted in down-regulation of ERCC1. The current results suggest that there is a complementary interaction between EGFR and ERCC1, and 5-FU-induced EGFR activation confers protection against radiation through activation of the DNA repair pathway.

In conclusion, interaction of EGFR and ERCC1 might correlate with radiation-induced DNA damage, when p53 mutant colon cancer cell lines are exposed to 5-FU followed by radiation. DNA repair may be emerging as an attractive central target in the mechanisms of chemoradiation in CRC, although further investigation is needed to elucidate the precise mechanism by which EGFR mediates the repair of radiation-induced DNA damage.

\section{References}

1. Bernier J, Cooper JS, Pajak TF, et al: Defining risk levels in locally advanced head and neck cancers: a comparative analysis of concurrent postoperative radiation plus chemotherapy trials of the EORTC (\#22931) and RTOG (\#9501). Head Neck 27: 843-850, 2005. 
2. Pignon JP, Arriagada R, Ihde DC, et al: A meta-analysis of thoracic radiation for small cell lung cancer. N Engl J Med 327: 1618-1624, 1992.

3. Herskovic A, Martz K, al-Sarraf M, et al: Combined chemotherapy and radiation compared with radiation alone in patients with cancer of the esophagus. N Engl J Med 326: 1593-1598, 1992.

4. Bleiberg H, Goffin J, Dalesio O, et al: Adjuvant radiation and chemotherapy in respectable gastric cancer: a randomised trial of the gastrointestinal tract cancer co-operative group of the EORTC. Eur J Surg Oncol 15: 535-543, 1989.

5. Adjuvant radiation for rectal cancer: a systematic overview of 8507 patients from 22 randomised trials. Colorectal Cancer Collaborative Group. Lancet 358: 1291-1304, 2001.

6. Mayer A, Takimoto M, Fritz E, et al: The prognostic significance of proliferating cell nuclear antigen, epidermal growth factor receptor, and mdr gene expression in colorectal cancer. Cancer 71: 2454-2460, 1993

7. Zlobec I, Vuong T, Hayashi S, et al: Simple and reproducible scoring system for EGFR in colorectal cancer: application to prognosis and prediction of response to preoperative brachytherapy. Br J Cancer 96: 793-800, 2007.

8. Li S, Kim JS, Kim JM, et al: Epidermal growth factor receptor as a prognostic factor in locally advanced rectal-cancer patients treated with preoperative chemoradiation. Int J Radiat Oncol Biol Phys 65: 705-712, 2006.

9. Chen DJ and Nirodi CS: The epidermal growth factor receptor: a role in repair of radiation-induced DNA damage. Clin Cancer Res 13: 6555-6560, 2007.

10. Schmidt-Ullrich RK, Dent P, Grant S, et al: Signal transduction and cellular radiation responses. Radiat Res 153: 245-257, 2000.

11. Tounekti O, Kenani A, Foray N, et al: The ratio of single- to double-strand DNA breaks and their absolute values determine cell death pathway. Br J Cancer 84: 1272-1279, 2001.

12. Vousden KH and Lu X: Live or let die: the cell's response to p53. Nat Rev Cancer 2: 594-604, 2002.

13. Ojima E, Inoue $\mathrm{Y}$, Watanabe $\mathrm{H}$, et al: The optimal schedule for 5-fluorouracil radiosensitization in colon cancer cell lines. Oncol Rep 16: 1085-1091, 2006.

14. Inoue Y, Tanaka K, Hiro J, et al: In vitro synergistic antitumor activity of a combination of 5-fluorouracil and irinotecan in human colon cancer. Int J Oncol 28: 479-486, 2006.

15. Inoue Y, Miki C, Watanabe H, et al: Schedule-dependent cytotoxicity of 5-fluorouracil and irinotecan in a colon cancer cell line. J Gastroenterol 41: 1149-1157, 2006.

16. Lammering G: Molecular predictor and promising target: will EGFR now become a star in radiation? Radiother Oncol 74: 89-91, 2005.

17. Toulany M, Dittmann K, Baumann M, et al: Radiosensitization of Ras-mutated human tumor cells in vitro by the specific EGF receptor antagonist BIBX1382BS. Radiother Oncol 74: 1117-1129, 2005.
18. Toulany M, Dittmann K, Krüger M, et al: Radioresistance of $\mathrm{K}$-Ras mutated human tumor cells is mediated through EGFRdependent activation of PI3K-AKT pathway. Radiother Oncol 76: 143-150, 2005.

19. Sartor CI: Biological modifiers as potential radiosensitizers: targeting the epidermal growth factor receptor family. Semin Oncol 27: 15-20, 2000.

20. Goh HS, Chan CS, Khine K and Smith DR: p53 and behaviour of colorectal cancer. Lancet 344: 233-234, 1994.

21. Toiyama Y, Inoue Y, Hiro J, et al: The range of optimal concentration and mechanisms of paclitaxel in radio-enhancement in gastrointestinal cancer cell lines. Cancer Chemother Pharmacol 59: 733-742, 2007.

22. Dittmann K, Mayer $\mathrm{C}$ and Rodemann HP: Inhibition of radiationinduced EGFR nuclear import by C225 (Cetuximab) suppresses DNA-PK activity. Radiother Oncol 76: 157-161, 2005.

23. Reed E: Platinum-DNA adduct, nucleotide excision repair and platinum based anti-cancer chemotherapy. Cancer Treat Rev 24: 331-344, 1998

24. Murray D and Rosenberg E: The importance of the ERCC1/ ERCC4 [XPF] complex for hypoxic-cell radioresistance does not appear to derive from its participation in the nucleotide excision repair pathway. Mutat Res 364: 217-226, 1996.

25. Wood RD, Mitchell M, Sgouros, et al: Human DNA repair genes. Science 291: 1284-1289, 2001.

26. You JS, Wang M and Lee SH: Biochemical analysis of damage recognition process in nucleotide excision repair. J Biol Chem 278: 7476-7485, 2003.

27. Houtsmuller AB, Rademakers S, Nigg AL, et al: Action of DNA repair endonuclease ERCC1/XPF in living cells. Science 284: 958-961, 1999

28. Warnecke-Eberz U, Metzger R, Miyazono F, et al: High specificity of quantitative excision repair cross-complementing 1 messenger RNA expression for prediction of minor histopathological response to neoadjuvant radiochemotherapy in esophageal cancer. Clin Cancer Res 10: 3794-3799, 2004

29. Melton DW, Ketchen AM, Nunez F, et al: Cells from ERCC1deficient mice show increased genome instability and a reduced frequency of S-phase-dependent illegitimate chromosome exchange but a normal frequency of homologous recombination. J Cell Sci 111: 395-404, 1998.

30. Murray D, Vallee-Lucic L, Rosenberg E, et al: Sensitivity of nucleotide excision repair-deficient human cells to ionizing radiation and cyclophosphamide. Anticancer Res 22: 21-26, 2002.

31. Britten RA, Liu D, Tessier A, et al: ERCC1 expression as a molecular marker of cisplatin resistance in human cervical tumor cells. Int J Cancer 89: 453-457, 2000. 